\title{
SITE SELECTION FOR FUTURE INDUSTRIAL INFRASTRUCTURE IN THE PROVINCE OF CONSTANTINE (ALGERIA)
}

\author{
Guellouh Sami, Kalla Mahdi, Filali Abdelwahhab, Habibi Yahyaoui
}

\begin{abstract}
Summary
The aim of this study is to select the appropriate sites for the designation of future industrial zones in the province of Constantine, Algeria, using a geographic information system (GIS) and Remote Sensing, including the appropriate technical and environmental requirements.

The identification of appropriate sites for the establishment of new industrial zones in alignment with a planning process based on a set of socio-economic and environmental information and instructions has become a key problem for planners.

The factors involved in the selection of sites are classified into two categories (exclusion factors and appreciation factors) to be able to identify the most appropriate areas for future industrial facilities in the province in question.
\end{abstract}

\section{Keywords}

Constantine $\bullet$ GIS $\bullet$ industrial zones $\bullet$ factors $\bullet$ remote sensing $\bullet$ selection of sites

\section{Introduction}

In the last few years, Algeria has experienced a remarkable private and public industrial development, always in evolution, which makes the analysis of the adequacy of the sites paramount to meeting the needs and the local requirements, and to reach a degree of acceptable efficiency in spatial decision making.

In a site selection process, the analyst strives to determine the optimum location that would satisfy the selection criteria. The selection process attempts to optimize a number of objectives desired for a specific facility [Aleksandar et al. 2014].

Many factors have to be implemented in the site selection process. The approach taken is to classify the full set of factors into two categories: exclusion factors and appraisal factors.

The first category of factors is intended to exclude areas that are ill adapted and unsuitable for the purpose, in order to eliminate locations not meeting the requirements.

The second category of factors ensures the identification of the spatial distribution of the areas, which are most suitable for industrial infrastructure, and most sought after. 
Essentially, the procedure is based on the use of Geographic Information Systems (GIS), and remote sensing. Despite advances in geographical studies, the methods of traditional geography have become insufficient to apprehend the current reality in all its complexity, considering technological and scientific changes that have happened in the last 30 years. [Kaushik et al. 2007] A GIS is a powerful tool designed for spatial analysis that provides functionality to capture, store, query, analyse, display and output geographic information. As such, it has big influence in spatial decision-making process [Aleksandar et al. 2014].

GISs are well established as giving competitive advantage and enhancing organizational decision-making in a wide array of functions, including improved information sharing and flows, better informed decision making, stronger competitive ability, greater analysis and understanding of problems, justification for decision made, improved visualization of data, cost saving, increased effectiveness, and better quality output [Heywood 2011].

The results of this particular analysis can be embodied in a decision-making tool for planners in the province of Constantine and therefore can considerably reduce the time and material resources devoted to finding suitable sites.

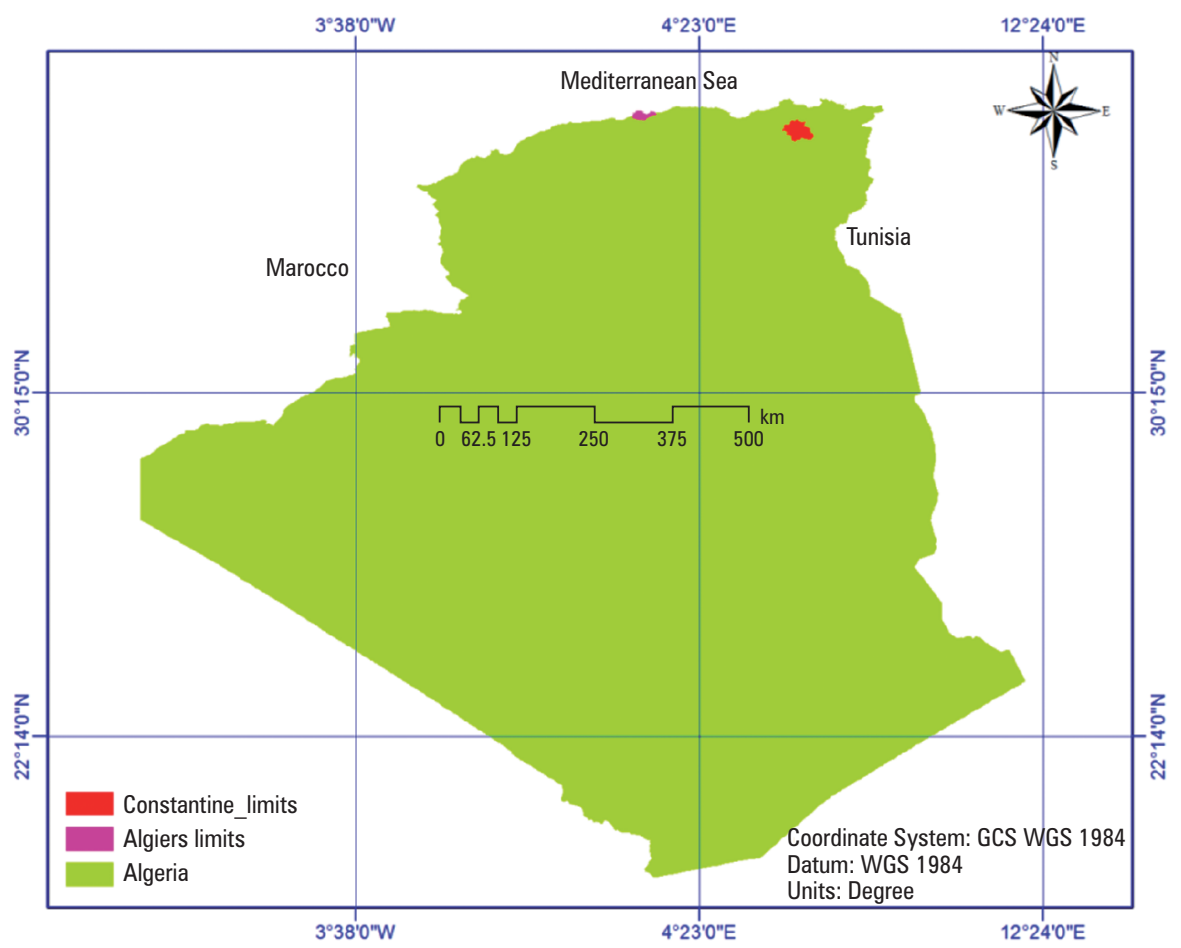

Source: Authors' own study

Fig. 1. Location of the study area 


\section{Geographic location}

The province of Constantine is located in Eastern Algeria; $431 \mathrm{~km}$ east of the capital, Algiers, between latitudes $35^{\circ} 7^{\prime}$ and $36^{\circ} 9^{\prime}$ North and between longitudes $6^{\circ} 20^{\prime}$ and $7^{\circ} 29^{\prime}$ East; and it covers an area of $2,248.44 \mathrm{~km}^{2}$.

\section{Material and methods}

Site location is a key factor and initial step in the design of many projects [Santosh et al. 2014]. It is a critical decision made by private and public property owners [Eldrandaly 2013]. The question of industrial location has long been at the heart of public reflection, whereas technological developments and territorial changes have long been the most salient indicators of industrial location [Savy 2007].

The main objective of this study is to identify appropriate sites for the establishment of industrial zones within the territory of the Constantine province, while eliminating areas that do not meet the desired criteria (exclusion criteria).

These constraints are intended to limit the search for appropriate sites in areas of exclusive character that do not tolerate competition [Aydi et al. 2012].

The exclusions factors adopted are as follows:

1. Exclusion of urban areas and a zone of $500 \mathrm{~m}$ in their proximity; these areas must be sufficiently far from the industrial area to avoid any type of nuisance.

2. Exclusion of the road network and a zone of $50 \mathrm{~m}$ in their proximity.

3. Exclusion of wadis and a zone of $500 \mathrm{~m}$ in their proximity.

4. Exclusion of protected areas (forests, agricultural land and water areas).

5. Exclusion of areas with a slope greater than $15 \%$.

The topographic features of an area are among the most important determinants to ascertain the suitability of an area for developmental activities. Severe limitations to subdivision development occur on slopes over $20 \%$. For industrial parks and commercial sites, slopes of more than $5 \%$ are preferred. Also, hilly terrain increases the cost; therefore, steep slopes are unfavourable [Santosh et al. 2014].

In order to identify the different classes of land cover information, we have developed a supervised classification of a Land Sat 8 satellite image (datum 2018), downloaded from USGS website.

The overall objective of the image classification procedure is to automatically categorize all pixels in an image into land cover classes or themes [Lillesand et al. 2008]. In Supervised Classification, the image analyst supervises the pixel categorization process by specifying, to the computer algorithm, numerical descriptors of various land cover types present in the image. Training samples that describe the typical spectral patterns of land cover classes are defined. [Ehsan 2009].

We note that the road network was downloaded in shapefile format from the Diva GIS database, while the slope and the hydrographic network (Wadis) were extracted in an analysis performed on a Digital Elevation Model (DEM), downloaded from the USGS website. 


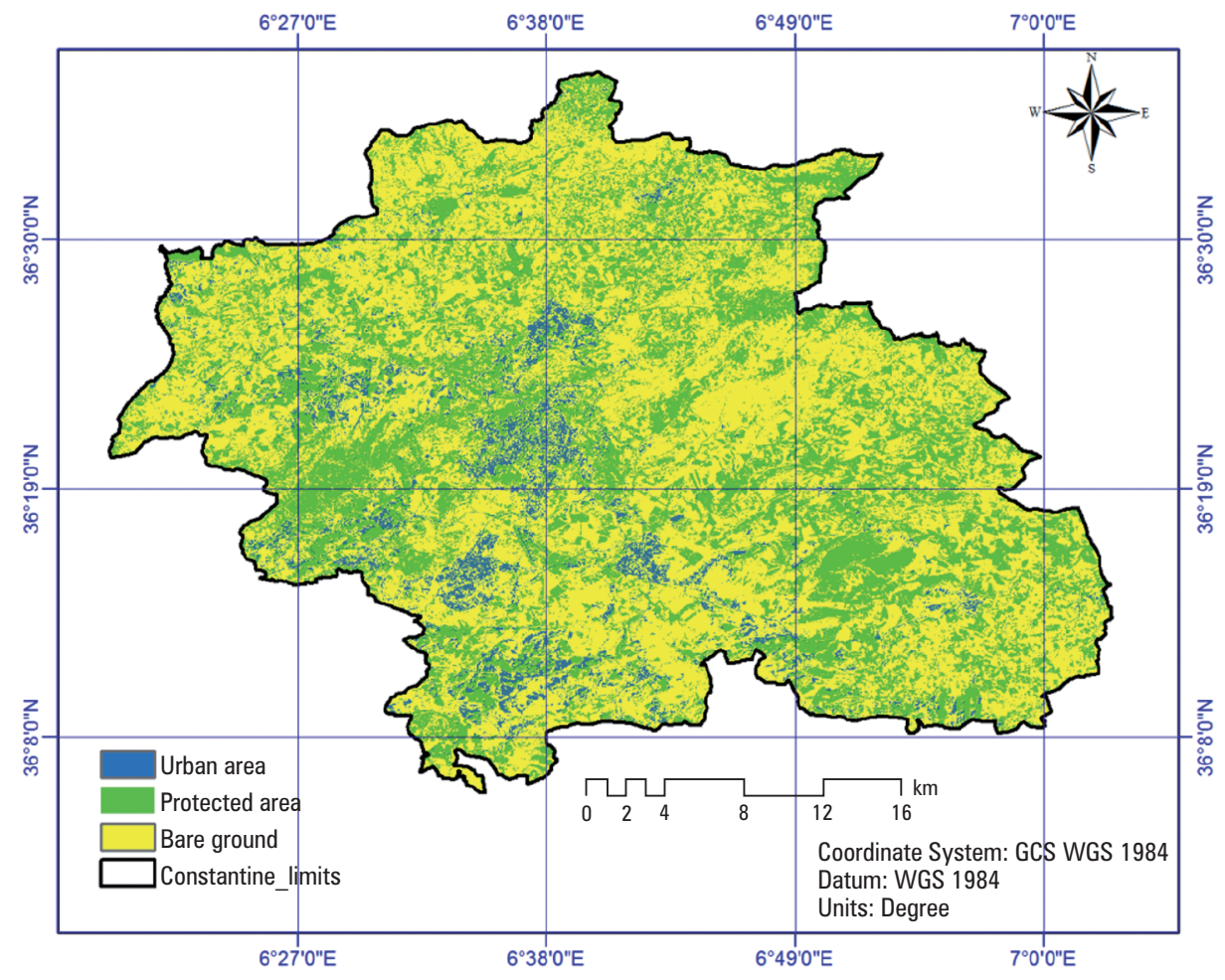

Source: Authors' own study

Fig. 2. Land use map

GIS allowed us to overlay several layers of information in order to exclude unsuitable areas. A GIS is a computer-based information system that enables the capture, modelling, storage, retrieval, sharing, manipulation, analysis, and presentation of geographically referenced data [Worboys et al. 2004].

To perform the operation, we used the Model Builder program, which is a visual programming language for developing geoprocessing workflows. Geoprocessing models can automate and document spatial analysis and data management processes. We can create and modify geoprocessing models in Model Builder, where a model is represented by a flowchart of process sequences and geoprocessing tools, using the output of one process as input to another process [Esri 2017].

In a site selection exercise, the analyst strives to determine the optimum location that would satisfy the proponents' selection criteria. The selection process attempts to optimize a number of objectives desired for a specific facility. Such optimization often involves numerous decision factors, which are frequently contradictory. As a result, the process often involves a number of possible sites, each having its specific advantages and limitations [Eldrandaly 2013]. 


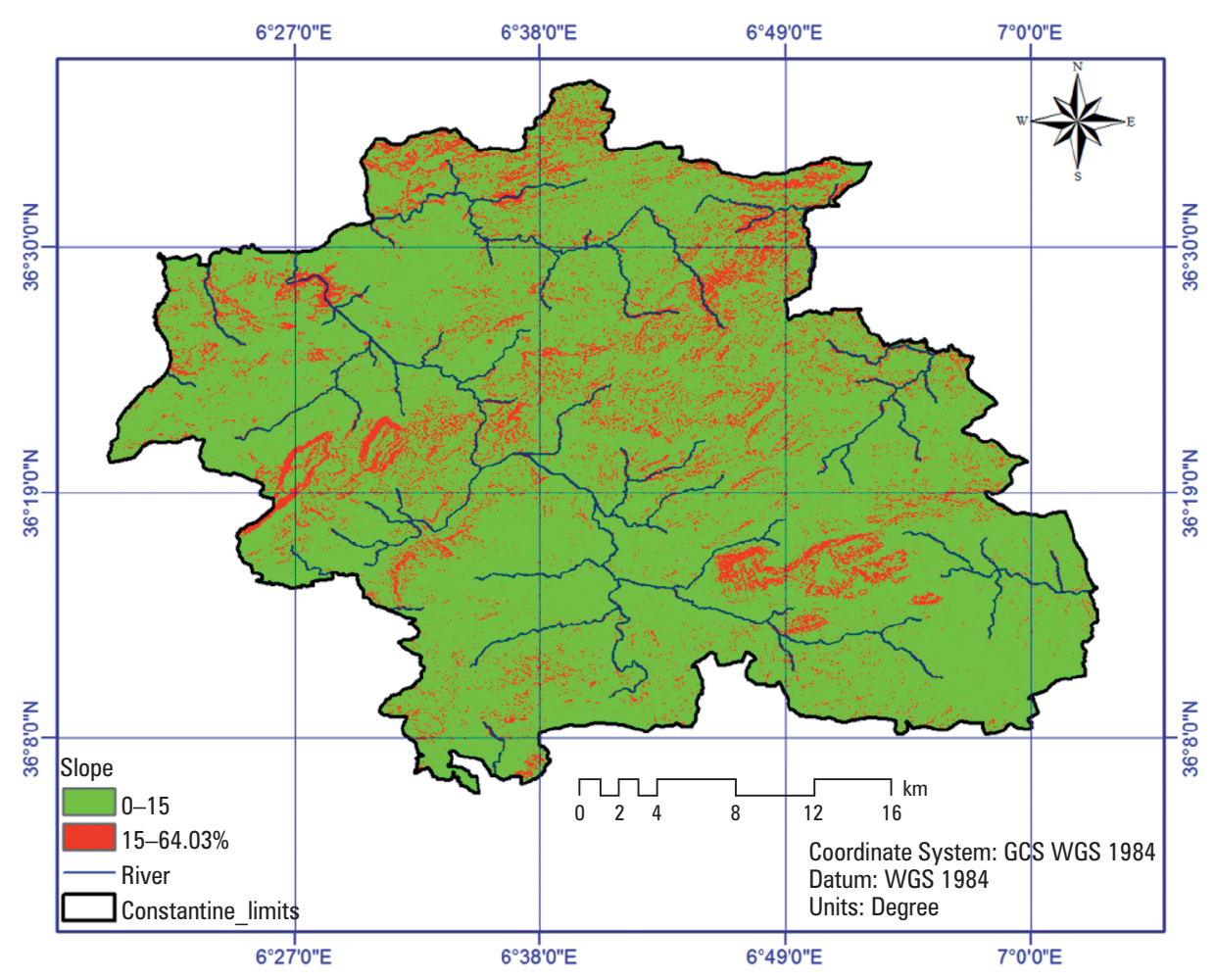

Source: Authors' own study

Fig. 3. Slope map

Following the primary selection of geographical areas of interest, we tried to single out the best sites for industrial areas set up using a spatial multi-criteria analysis.

Irrespective of spatial data organization, the ultimate aim of GIS is to provide support for spatial decisions [Aleksandar et al. 2014]. The multi-criteria decision-making procedures define a relationship between "input maps" and "output maps" [Malczewski 2006]. One of the most important rules governing the use of GIS for spatial decision support systems is that GIS themselves do not make decisions - people do [Aleksandar et al. 2014]. Multi-criteria spatial analysis is a method of spatial analysis that combines several criteria, of different natures, in order to obtain a cartographic result defining areas able, as much as possible, to respond to the expectations [Balzarini et al. 2011].

The weighted linear combination (WLC) method has been used to determine suitable areas. The WLC is the most common technique for analysing multi-scale evaluations. This technique also is called a "scoring method", and it is based on the content of the weight average [Hamidreza 2015]. The analyser or decision-maker is based on the "relative importance" weighted directly to the scales. By multiplying the relative weight by the feature value, a final measure can be obtained for each option (such as picture 
element in spatial analysis). After specifying the final value for each option, alternatives that have higher values will be the best options for the desired outcome [Malczewski 2006].

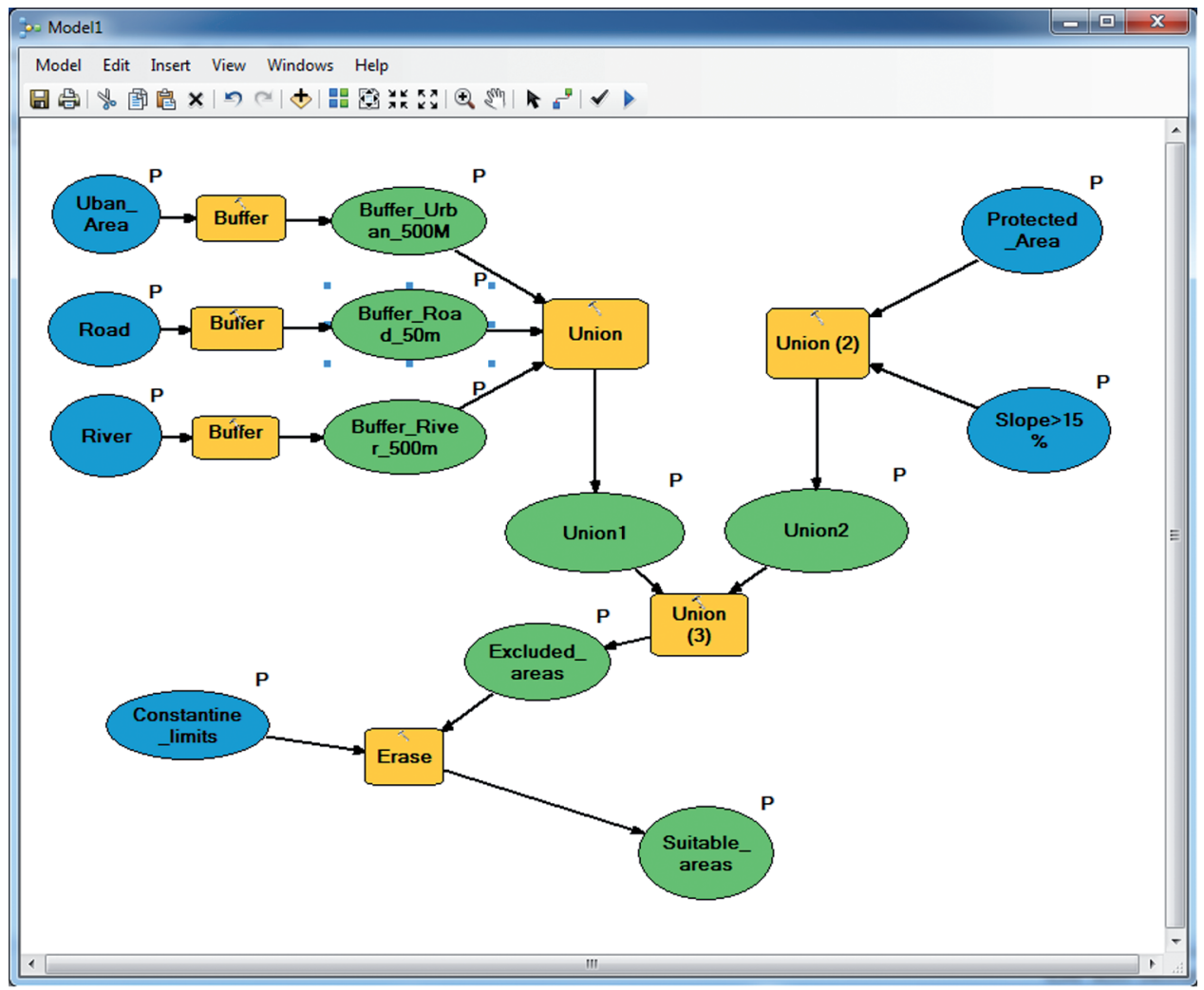

Source: Authors' own study

Fig. 4. Model builder

Determining the proportion for a specific operation or evaluating the potential of a particular occurrence is considered to be a desired outcome [Hamidreza 2015]. WLC is defined and implemented as follows: For a given set of criteria, WLC is defined as a combination procedure that associates a set of criteria weights with the $i$-th decision alternative (the location or polygon), where the weights satisfy the following properties: $w_{1}, w_{2}, \ldots, 0 \leq w k \leq 1$ and $\sum_{k=1}^{n} w k=1, k=1,2,3, \ldots, n$. The weights are multiplied by the criterion values $a_{i 1}, a_{i 2}, \ldots, a_{i n},=1,2, \ldots, m$ as in Equation (1) [Steffan 2016]:

$$
\operatorname{WLC}(A i)=\sum_{k=1}^{n} w k \cdot V(a i k)
$$


Two important economic factors (slope and distance to major highways) have been retained, and both factors have been considered to contribute in the same way to the assessment of the sites selected in the previous analysis.

To ensure better accessibility and to facilitate the movement and transport of raw material and finished products intended for trade, the location of the industrial units must be adjacent to the main road network, because the elevated costs of building a new road should be taken into consideration.

Slope is an important criterion in the process of selecting appropriate sites. Areas with steep slopes and uneven terrain are disadvantageous because they increase the cost of construction.

Table 1. Appreciation factors

\begin{tabular}{|c|c|c|}
\hline \multirow{4}{*}{ Factors } & Classes & Codes \\
\hline \multirow{3}{*}{ Road distance $[\mathrm{km}]$} & $0-3$ & 0.25 \\
\cline { 2 - 3 } & $0-6$ & $\mathbf{0 . 5}$ \\
\cline { 2 - 3 } & $0-9$ & 0.75 \\
\cline { 2 - 3 } & $9-12$ & 1 \\
\hline \multirow{3}{*}{ Slope [\%] } & $0-3$ & 0.25 \\
\cline { 2 - 3 } & $3-6$ & $\mathbf{0 . 5}$ \\
\cline { 2 - 3 } & $6-9$ & 0.75 \\
\cline { 2 - 3 } & $9-15$ & 1 \\
\hline
\end{tabular}

\section{Results and discussion}

The spatial analysis carried out has led us to construct a geographic database with the purpose of selecting the appropriate areas for the installation of industrial units.

Table 2. Classes of suitable areas

\begin{tabular}{|c|c|c|}
\hline WLC results & Suitability level & Areas $\left[\mathrm{km}^{2}\right]$ \\
\cline { 1 - 1 } 0.25 & \multirow{2}{*}{ Very suitable areas } & 7.059 \\
\cline { 1 - 1 } 0.375 & Suitable areas & 4.867 \\
\cline { 1 - 1 } 0.5 & Less suitable areas & \multirow{2}{*}{10.962} \\
\cline { 1 - 1 } 0.625 & \multirow{2}{*}{ Poorly suitable areas } & 0 \\
\cline { 1 - 1 } 0.875 & & 0.276 \\
\hline
\end{tabular}




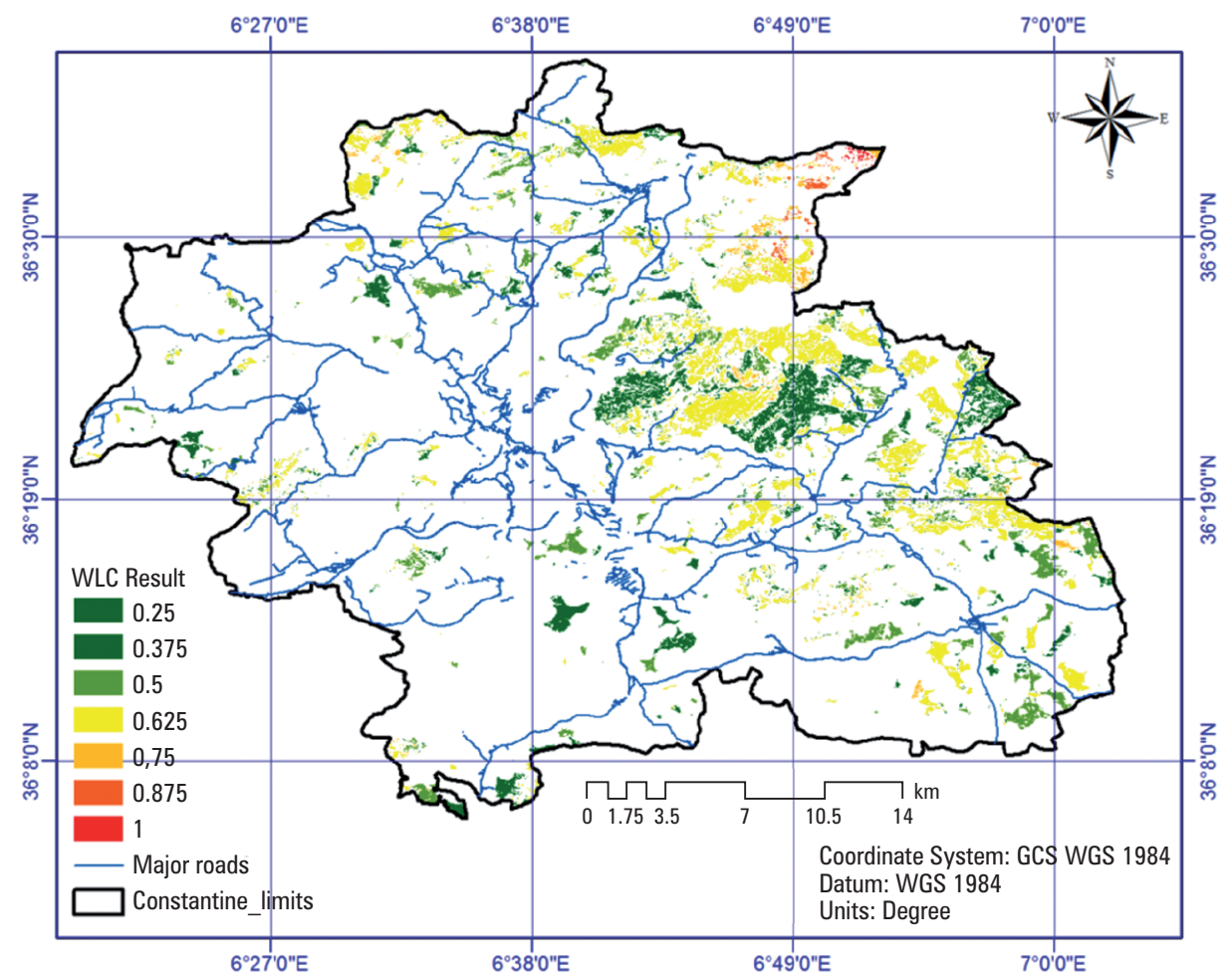

Source: Authors' own study

Fig. 5. Suitable areas

After applying spatial analysis to the relevance and the appreciation factors, we have found that the total area responding to the exclusion factors involved is $23,164 \mathrm{~km}^{2}$ of which $30.47 \%$ represent areas of very good suitability, $21.01 \%$ are appropriate areas, $47.32 \%$ are areas of moderate suitability, and $1.19 \%$ correspond to poorly suitable areas.

\section{Conclusion}

Site selection is a crucial topic in facility installation processes. This work aims, on the one hand, to develop a decision support tool for the installation of industrial units, and on the other hand, to support environmental preservation surveys.

The core of this study is based on geospatial data processing of the study area using a GIS to select the most suitable areas for the installation of the infrastructure in question. This has been achieved by identifying a set of factors classed into two categories (exclusion factors and appraisal factors).

The present study must be reinforced by other factors such as the inclusion of various networks, for instance the electricity and gas networks, and the location of controlled 
landfills to minimize the costs of production. Moreover, in the case of specific chemical industrial sites, the exclusion parameters of proximity zones must be carefully defined and followed, in order to ensure a good protection and a better preservation of the environment.

\section{References}

Abdelwaheb A., Moncef Z., Hamed B. 2012. Apport du SIG et des méthodes d'analyse multicritère pour le choix de site de stockage de margine. Géomatique Expert, 86, 38.

Aleksandar R., Ilija C., Djordje L. 2014. GIS Based Multi-Criteria Analysis for Industrial Site Selection. 24th DAAAM International Symposium on Intelligent Manufacturing and Automation, 2013. Science Direct Procedia Engineering, 69, 1054-1063.

Ehsan G. 2009. Current Application of Remote Sensing Techniques in Land Use Mapping: A Case Study of Northern Parts of Kolhapur District. India J. Appl. Sci. Environ. Manag. December, 13(4), 15-20.

ESRI. 2017. Qu'est-ce que un model builder? https://pro.arcgis.com/fr/proapp/help/analysis/ geoprocessing/modelbuilder/what-is-modelbuilder-.htm

Hamidreza J., Saeed K., Mehrdad N. 2015. Nuclear power plant locating by WLC and GIS (Case study: Iran Hormozgan province). International Journal of Basic and Applied Sciences, 4(1), $132-139$.

Heywood I., Corneliues S., Carver S. 2011. An Introduction to Geographical Information Systems. Pearson, London.

Kaushik K. Shandilya, Shukla S.P., Pathak V. 2007. Applications of remote sensing. Horizons in Earth Science Research, 10, 1-9.

Khalid E. 2013. Developing a GIS-Based MCE Site Selection Tool in Arc GIS Using COM Technology. The International Arab Journal of Information Technology, 10(3).

Lillesand T.M., Kiefer R., Wand Chipman J.W. 2008. Remote sensing and image interpretation. John Wiley \& Sons, Inc., New York.

Malczewski J. 2006. GIS-based multi-criteria decision analysis: a survey of the literature. International Journal of Geographical Information Science, 20(7), 703-726.

Malczewski J. 2006. Ordered weighted averaging with fuzzy quantifiers: GIS-based multi criteria evaluation for land-use suitability analysis. International Journal of Applied Earth Observation and Geoinformation, 8, 270-277.

Ministerio da Educacao e Cultura (MEC). 1999. Secretaria de Educacao Media e Tecnologica. Parametros Curriculares Nacionais, EnsinoMedio, Brasilia, 188.

Raffaella B., Paule-Annick D., Muriel N. 2011. Evolution et développement des méthodes d'Analyse spatiale multicritère pour des modèles d'aptitude: l'exemple des applications en Géosciences. Laboratoire d'Informatique de Grenoble (LIG) équipes Steamer et Metah. ESRI France, Département Education et Recherche.

Santosh K., Ritesh K. 2014. Site Suitability Analysis for Urban Development of a Hill Town Using GIS Based Multicriteria Evaluation Technique: A Case Study of Nahan Town, Himachal Pradesh, India. International Journal of Advanced Remote Sensing and GIS, 3(1), 516-524.

Savy M. 2006. Territoire: les lieux de la démocratie. Hommes \& Libertes, 137.

Steffan V. 2016. Manuel d'utilisation de MCDA4ArcMap, version 1.1 A. Created on Wednesday, February 24.

Worboys M., Duckham M. 2004. GIS: A Computing Perspective. CRC Press, Florida. 
Dr. Guellouh Sami

University of Batna 02, Algeria

Laboratory LRNAT

e-mail: s.guellouh@univ-batna2.dz

Pr. Kalla Mahdi

University of Batna 02, Algeria

Laboratory LRNAT

e-mail:m.kalla@univ-batna2.dz

Dr. Filali Abdelwahhab

University of Batna 02, Algeria

Laboratory LRNAT

e-mail: a.filali@univ-batna2.dz

Dr. Habibi Yahyaoui

University of Batna 02, Algeria

Laboratory LRNAT

e-mail: y.habibi@univ-batna2.dz 